\title{
Enhanced production of vascular endothelial growth factor by human monocytic cells stimulated with endotoxin through transcription factor SP-1
}

\author{
TETSUYA SAKUTA, KENJI MATSUSHITA, NOBORU YAMAGUCHI*, TOHRU OYAMA, RIE MOTANI, \\ TOSHIHIKO KOGA*, SHIGETAKA NAGAOKA, KAZUHIRO ABEYAMA $\dagger$, IKURO MARUYAMA†, \\ HARUHIKO TAKADA $\$$ and MITSUO TORII
}

Department of Operative Dentistry and Endodontology, Kagoshima University Dental School, Kagoshima 8908544, * Department of Preventive Dentistry, Kyushu University Faculty of Dentistry, Fukuoka 812-8582,

$\uparrow$ Department of Clinical Laboratory Medicine, Kagoshima University Medical School, Kagoshima 890-8520 and $\$$ Department of Microbiology and Immunology, Tohoku University School of Dentistry, Sendai 980-8575, Japan

\begin{abstract}
The effect of endotoxin on the regulation of vascular endothelial growth factor (VEGF) mRNA expression in human monocytic (THP-1) cells was examined. Endotoxic lipopolysaccharide (LPS) from Escherichia coli and synthetic E. coli-type lipid A (LA15-PP) enhanced VEGF mRNA expression. LPS-induced VEGF mRNA accumulation was regulated, at least in part, at the transcriptional level. Enhancement of VEGF gene expression by LPS was shown by gel shift analysis and use of transcription factor inhibitors to be mediated via the activation of SP-1.
\end{abstract}

\section{Introduction}

Monocytes are major contributors to the regulation of wound repair and immune responses. Stimulation of monocytes with endotoxin (lipopolysaccharide, LPS) leads to a rapid and transient expression of genes encoding proteins with immunomodulatory activities [1]. Vascular endothelial growth factor (VEGF) is an angiogenic factor that induces endothelial cell proliferation and angiogenesis which enhances vascular permeability [2]. VEGF is induced by hypoxia [3] or several cytokines [4-6] in various normal and transformed cells. Recently, LPS was shown to induce VEGF production in murine peritoneal macrophages [7] and peripheral blood mononuclear cells isolated from patients with rheumatoid arthritis [8]. Furthermore, it was also found that VEGF was chemotactic for monocytes [9]. Therefore, VEGF may be involved in the immune response at infected sites. However, little is known about the regulation of molecular mechanisms governing VEGF gene expression by LPS. The present study examined whether synthetic lipid A enhanced VEGF mRNA expression and whether activation of SP-

Received 8 March 2000; revised version received 15 Aug. 2000; accepted 6 Sept. 2000.

Corresponding author: Dr M. Torii (e-mail: toriim@dentb. hal.kagoshima-u.ac.jp).
1 was involved in the enhanced expression of VEGF in human monocytic cells in response to LPS.

\section{Materials and methods \\ Cell culture}

Human monocytic THP-1 cells were obtained from the American Type Culture Collection (ATCC, Rockville, MD, USA). The cells were maintained in RPMI 1640 (Gibco Laboratories, Grand Island, NY, USA) supplemented with fetal bovine serum (FBS; Gibco) $10 \%$ and kanamycin $200 \mu \mathrm{g} / \mathrm{ml}$ in a humidified atmosphere of air with $\mathrm{CO}_{2} 5 \%$ at $37^{\circ} \mathrm{C}$. The cells were treated with $100 \mathrm{nM} 1 \alpha, 25$-dihydroxyvitamin $\mathrm{D}_{3}$ at a density of $2 \times 10^{6}$ cells $/ \mathrm{ml}$ at $37^{\circ} \mathrm{C}$, and then were stimulated with test materials in the following experiments.

\section{Specimens and probes}

LPS from Escherichia coli O55:B5, cycloheximide, actinomycin D and mithramycin A were purchased from Sigma (Sigma Chemical Co., St. Louis, MO, USA). Curcumin was purchased from Nakarai Tesque (Kyoto, Japan). Synthetic Escherichia coli-type lipid A (LA-15-PP) [10] and murine monoclonal anti-CD14 antibody (MAb MY4) were obtained from Daiichi Pure Chemical Co. (Tokyo, Japan) and Coulter (Hialeah, FL, 
USA), respectively. Plasmids containing human VEGF cDNA sequence [11] were provided by Dr M. Shibuya (Faculty of Pharmaceutical Sciences, University of Tokyo, Tokyo). A human glyceraldehyde-3-phosphate dehydrogenase (GAPDH) cDNA clone [12] was provided by Dr S. Sakiyama (Chiba Cancer Center Research Institute and Hospital, Chiba, Japan).

\section{Northern blot analysis}

Total RNA extraction and Northern blot analysis were performed as described previously [13]. Filters were then exposed to the imaging plate for analysis with a Bio-Imaging Analyzer (BAS 1000 Mac; Fuji Photo Film, Tokyo). Data were normalised by expressing the ratio of VEGF mRNA to GARDH mRNA.

\section{Gel shift assay}

Nuclear extracts were prepared according to Chomczynski and Sacchi [14]. Gel shift assays were performed as described by Jimi et al. [15]. DNA binding was assayed with consensus AP-1 elements, TTGATGACTCA and consensus SP-1 elements, GATCGGGGCGGGGC.
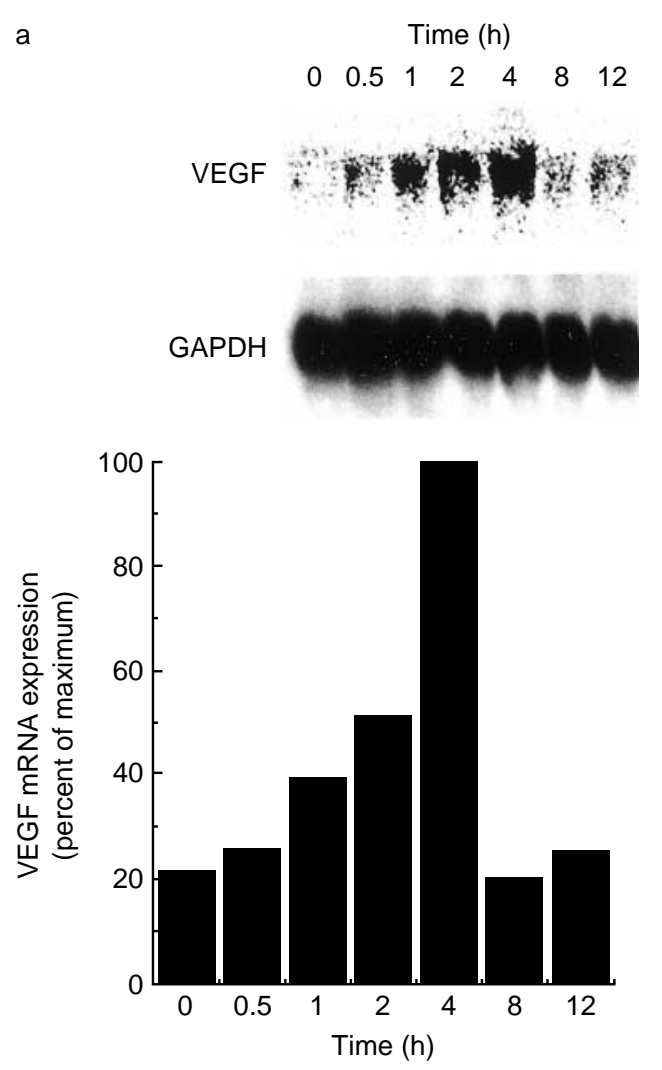

a

\section{Measurement of VEGF protein}

The concentrations of $\mathrm{VEGF}_{165}$ protein in the culture supernates were measured by ELISA at the Tukuba Research Laboratories of Toagosei Co. (Ibaraki, Japan).

\section{Results}

Effect of LPS and synthetic lipid $A$ on VEGF mRNA expression in THP-1 cells

The effect of LPS from E. coli on the expression of VEGF mRNA by THP-1 cells was examined. VEGF mRNA expression began to increase after exposure for $30 \mathrm{~min}$, reached a maximum level within $4 \mathrm{~h}$, then decreased to a normal level within $8 \mathrm{~h}$ (Fig. 1). In accordance with the gene expression, VEGF secretion from the cells was significantly enhanced from 8 to $48 \mathrm{~h}$ (Fig. 1). In human peripheral blood mononuclear cells, VEGF production in the cultures incubated with LPS, as determined by the ELISA, was about two-fold higher than in those without LPS (data not shown). To elucidate the active entity of LPS, THP-1 cells were incubated with LA-15-PP, which also enhanced VEGF mRNA expression by THP-1 (Fig. 2). Enhanced

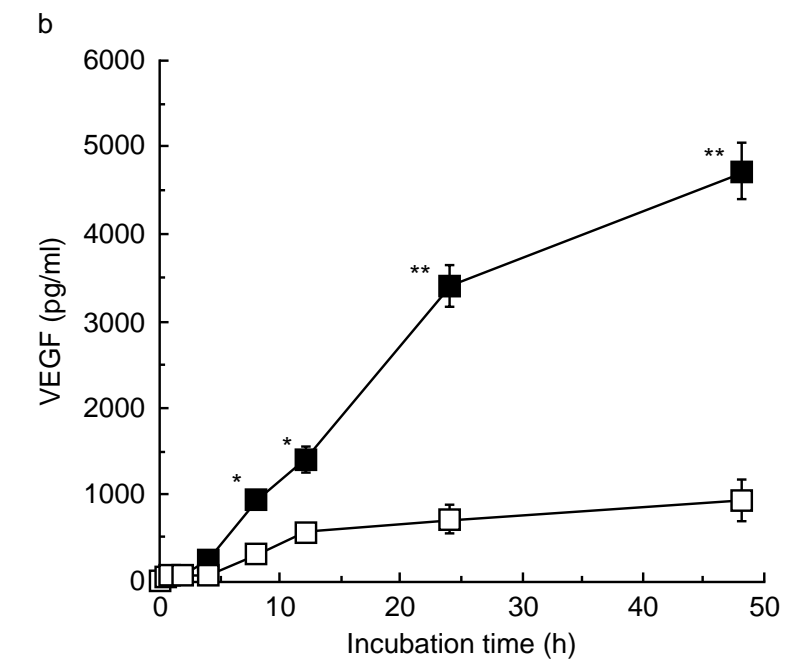

Fig. 1. Time course of VEGF mRNA induction in THP-1 cells stimulated with E. coli LPS $1 \mu \mathrm{g} / \mathrm{ml}$ for the indicated periods. (a) Total RNA was extracted and was hybridised with ${ }^{32}$ P-labelled VEGF and GAPDH cDNA probes. Two additional experiments showed similar findings. (b) Culture media were collected and the VEGF concentration was determined by ELISA. The data presented are representative of three experiments that gave essentially identical results. Differences from the respective controls (medium alone) were significant at $\mathrm{p}<0.05(*)$ and $\mathrm{p}<0.01\left({ }^{* *}\right)$ by Student's $t$ test. 


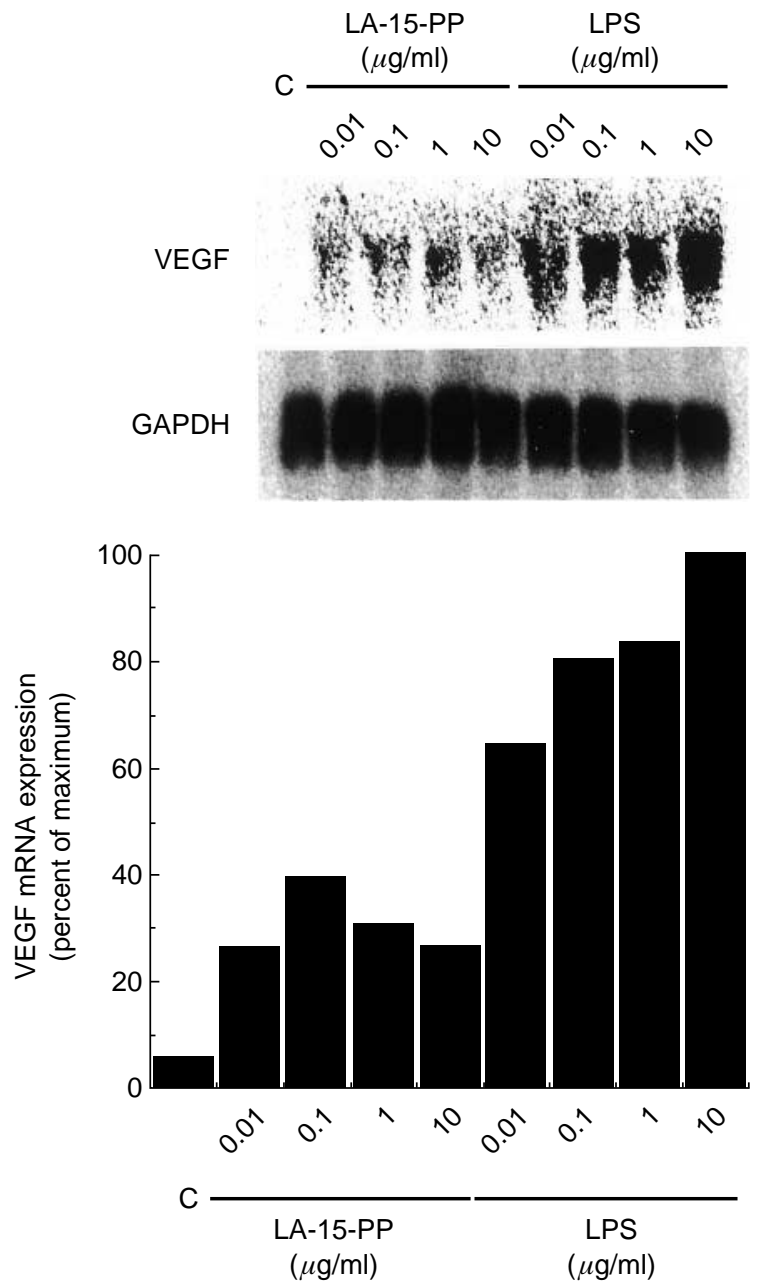

Fig. 2. Dose response of VEGF mRNA expression in THP-1 cells stimulated with LPS and LA-15-PP for $4 \mathrm{~h}$; $\mathrm{C}$, negative control. Other details are as given in the footnote to Fig. 1.

expression of VEGF mRNA by THP-1 cells induced by LPS was markedly suppressed in the presence of MAb MY4 (Fig. 3). These findings indicated that LPS enhanced VEGF mRNA expression by THP-1 cells through a CD14-dependent pathway.

\section{Enhanced VEGF mRNA expression and SP-1 activation}

To further investigate the mechanisms of enhanced VEGF mRNA expression induced by LPS, cycloheximide or actinomycin D was added to the THP-1 cultures. LPS-induced VEGF mRNA expression was not suppressed by cycloheximide, but was inhibited by actinomycin D (Fig. 4). This finding showed that part of the enhanced expression of VEGF mRNA was induced by LPS directly and might be mediated at the transcriptional level, while there is a possibility that VEGF mRNA accumulation was due to the increase of mRNA stability and was modulated via production of factor(s) stimulated by LPS.

To examine the possible transcriptional regulation of LPS-induced VEGF mRNA expression, gel shift assays
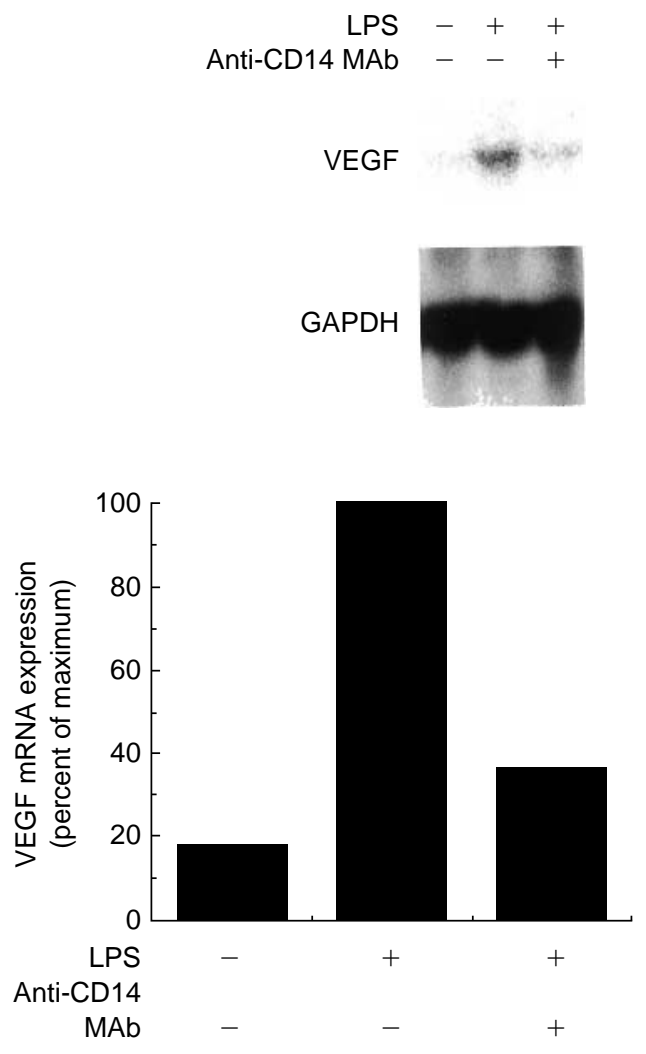

Fig. 3. Effect of anti-CD14 antibody on LPS-induced VEGF mRNA expression by THP-1 cells incubated for $4 \mathrm{~h}$ with or without $E$. coli LPS $1 \mu \mathrm{g} / \mathrm{ml}$ or MAb MY4 $2.5 \mu \mathrm{g} / \mathrm{ml}$ or both. Other details are as given in the footnote to Fig. 1. Similar findings were obtained in two other experiments.

were performed. LPS-induced AP-1 activation began to increase slightly after exposure for $30 \mathrm{~min}$, reached the maximum level after $4 \mathrm{~h}$ and was maintained until $12 \mathrm{~h}$ (Fig. 5a). In contrast, LPS-induced SP-1 activation began to increase after $15 \mathrm{~min}$ and reached the maximum level within $30 \mathrm{~min}$ (Fig. 5b), which was faster than LPS-induced VEGF mRNA expression. These DNA bindings were specific, because excess amounts of the unlabelled wild-type oligonucleotide, but not the mutated oligonucleotide, competitively inhibited these activities (data not shown).

To determine how transcription factors regulate the LPS-induced VEGF mRNA expression, THP-1 cells were incubated with LPS in the presence or absence of curcumin and mithramycin A, inhibitors of AP-1 activation [16] and SP-1 activation [6], respectively. Mithramycin A suppressed LPS-induced VEGF mRNA expression, whereas curcumin did not alter the expression of VEGF mRNA (Fig. 6), indicating involvement of SP-1 in LPS-induced VEGF mRNA expression by THP-1 cells.

\section{Discussion}

VEGF has been shown to be a key mediator of neovascularisation associated with tumours and intra- 

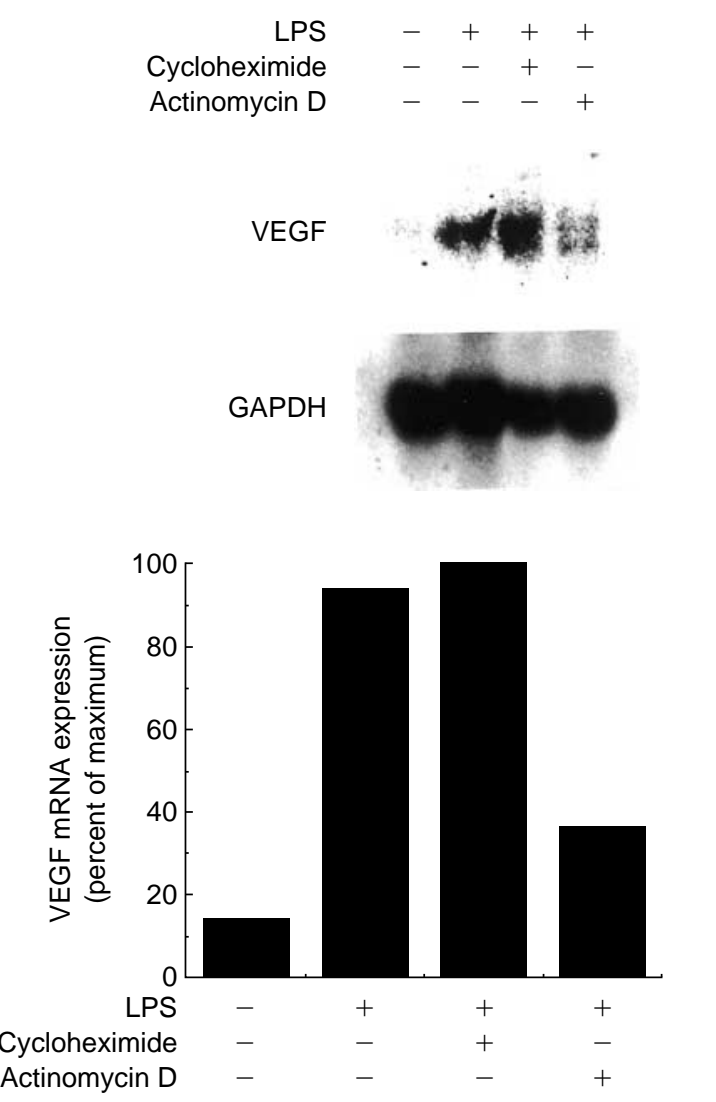

Fig. 4. Effects of cycloheximide and actinomycin D on LPS-induced VEGF mRNA expression by THP-1 cells incubated for $4 \mathrm{~h}$ with or without E. coli LPS $1 \mu \mathrm{g} / \mathrm{ml}$, cycloheximide $10 \mu \mathrm{g} / \mathrm{ml}$ or actinomycin D $10 \mu \mathrm{g} / \mathrm{ml}$. Other details are as given in the footnote to Fig. 1. Similar findings were obtained in two other experiments.

ocular disorders [2]. Furthermore, Brown et al. [17] reported that VEGF mRNA was overexpressed in the epidermis of healing skin wounds. VEGF is induced by hypoxia [3], tumour necrosis factor- $\alpha$ (TNF- $\alpha$ ) [5, 6], interleukin-6 [4] or platelet-derived growth factor [18] in various normal and transformed cell types. Xiong et al. [7] reported that co-stimulation with LPS and interferon- $\gamma$ induced VEGF production and mRNA expression in murine peritoneal macrophages, but a recent study showed that VEGF production was enhanced by LPS alone [19]. Similar findings have been reported with peripheral blood mononuclear cells from patients with rheumatoid arthritis [8] and rheumatoid synovial cells [20]. In accordance with other endotoxic activities, induction of VEGF gene expression in human monocytic cells by LPS was reproduced by the lipid A portion (Fig. 2) and proceeded through a CD14-dependent pathway (Fig. $3)$. In the VEGF promoter region, several binding sites for the transcription factors SP-1, AP-1 and AP-2 were suggested [21]. The enhanced expression of the VEGF gene induced by basic fibroblast growth factor (bFGF) and TNF- $\alpha$ was mediated through transcription factor SP-1 in human glioma cells [6].

Recently, enhanced production of VEGF in human pulp

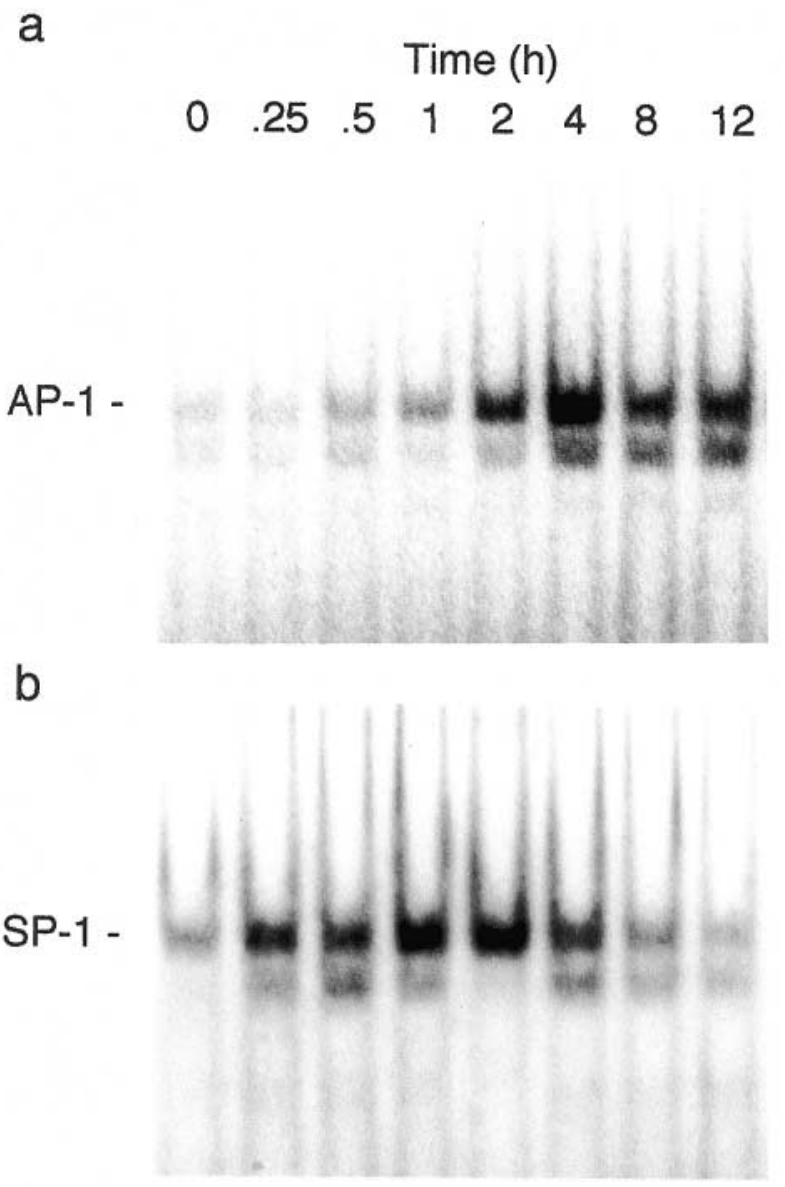

Fig. 5. Effects of LPS on nuclear binding to AP-1 and SP-1 consensus fragments. THP-1 cells were stimulated with E. coli LPS $1 \mu \mathrm{g} / \mathrm{ml}$ for the indicated periods. The nuclear extracts were prepared and gel shift assay was performed as described in the text. Two other experiments showed similar findings.

cells was shown to be mediated, in part, through AP-1 activation [19]. However, the present study provides the first evidence that enhanced expression of the VEGF gene induced by LPS is mediated via the activation of SP-1 in human monocytic cells (Figs. 5 and 6). These different findings regarding the activation of the transcription factor in response to LPS may depend on the target cells. In inflammatory tissues, host cells release various cytokines in response to invading bacteria and their components and products. It has been shown that monocyte chemotaxis in response to VEGF was mediated by flt-1, which is one of the VEGF receptors and, futhermore, that exposure of human monocytes to LPS led to a significant upregulation of the flt-1 mRNA level [9]. In our studies, VEGF showed chemotaxis for human peripheral mononuclear cells (unpublished observation). Therefore, it appears that, at infected sites, monocyte/macrophage-derived VEGF produced in response to LPS might stimulate surrounding monocytes to migrate into the infected region, resulting in wound healing and induction of inflammatory angiogenesis. 


$\begin{array}{rllll}\text { LPS } & - & + & + & + \\ \text { Mithramycin A } & - & - & + & - \\ \text { Curcumin } & - & - & - & +\end{array}$

VEGF

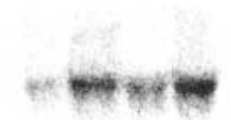

GAPDH
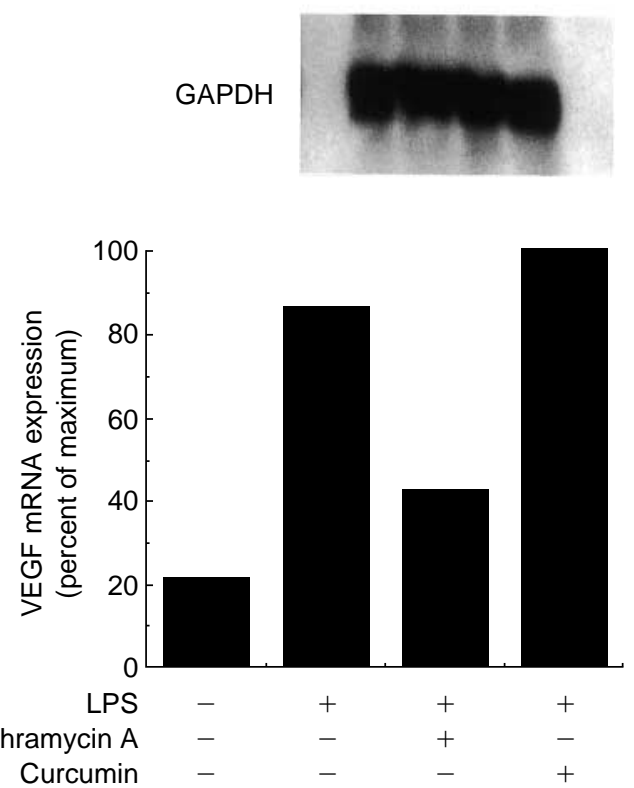

Fig. 6. Effects of mithramycin A and curcumin on LPSinduced VEGF mRNA expression by THP-1 cells incubated for $4 \mathrm{~h}$ with or without $E$. coli LPS $1 \mu \mathrm{g} / \mathrm{ml}$, $10 \mathrm{nM}$ mithramycin A or $5 \mu \mathrm{M}$ curcumin. Other details are as given in the footnote to Fig. 1. Similar findings were obtained in two other experiments.

We thank D. Mrozek (Medical English Service, Kyoto, Japan) for reviewing this paper. This work was supported in part by grants from the Grants-in-Aid for Scientific Research (09771630) from the Ministry of Education, Science, Sports, and Culture of Japan.

\section{References}

1. Ziegler-Heitbrock H-WL. The biology of the monocyte system. Eur J Cell Biol 1989; 49: 1-12.

2. Ferrara N, Davis-Smyth T. The biology of vascular endothelial growth factor. Endocr Rev 1997; 18: 4-25.

3. Levy AP, Levy NS, Goldberg MA. Post-transcriptional regulation of vascular endothelial growth factor by hypoxia. J Biol Chem 1996; 271: 2746-2753.

4. Cohen T, Nahari D, Cerem LW, Neufeld G, Levi B-Z. Interleukin 6 induces the expression of vascular endothelial growth factor. $J$ Biol Chem 1996; 271: 736-741.

5. Frank S, Hübner G, Breier G, Longaker MT, Greenhalgh DG, Werner S. Regulation of vascular endothelial growth factor expression in cultured keratinocytes: implications for normal and impaired wound healing. J Biol Chem 1995; 270: $12607-$ 12613.

6. Ryuto $\mathrm{M}$, Ono $\mathrm{M}$, Izumi $\mathrm{H}$ et al. Induction of vascular endothelial growth factor by tumor necrosis factor $\alpha$ in human glioma cells: possible roles of SP-1. J Biol Chem 1996; 271: 28220-28228.

7. Xiong M, Elson G, Legarda D, Leibovich SJ. Production of vascular endothelial growth factor by murine macrophages. Regulation by hypoxia, lactate, and the inducible nitric oxide synthase pathway. Am J Pathol 1998; 153: 587-598.

8. Bottomley MJ, Webb NJA, Watson CJ, Holt PJ, Freemont AJ, Brenchley PEC. Peripheral blood mononuclear cells from patients with rheumatoid arthritis spontaneously secrete vascular endothelial growth factor (VEGF): specific up-regulation by tumour necrosis factor-alpha (TNF- $\alpha$ ) in synovial fluid. Clin Exp Immunol 1999; 117: 171-176.

9. Barleon B, Sozzani S, Zhou D, Weich HA, Mantovani A, Marmé D. Migration of human monocytes in response to vascular endothelial growth factor (VEGF) is mediated via the VEGF receptor flt-1. Blood 1996; 87: 3336-3343.

10. Imoto M, Yoshimura H, Shimamoto T, Sakaguchi N, Kusumoto S, Shiba T. Total synthesis of Escherichia coli lipid A, the endotoxically active principle of cell-surface lipopolysaccharide. Bull Chem Soc Jpn 1987; 60: 2205-2214.

11. Yamane A, Seetharam L, Yamaguchi $\mathrm{S}$ et al. A new communication system between hepatocytes and sinusoidal endothelial cells in liver through vascular endothelial growth factor and Flt tyrosine kinase receptor family (Flt-1 and KDR/Flk-1). Oncogene 1994; 9: 2683-2690.

12. Tokunaga k, Nakamura Y, Sakata $\mathrm{K}$ et al. Enhanced expression of a glyceraldehyde-3-phosphate dehydrogenase gene in human lung cancers. Cancer Res 1987; 47: 5616-5619.

13. Tamura M, Tokuda M, Nagaoka S, Takada H. Lipopolysaccharides of Bacteroides intermedius (Prevotella intermedia) and Bacteroides (Porphyromonas) gingivalis induce interleukin-8 gene expression in human gingival fibroblast cultures. Infect Immun 1992; 60: 4932-4937.

14. Chomczynski P, Sacchi N. Single-step method of RNA isolation by acid guanidinium thiocyanate-phenol-chloroform extraction. Anal Biochem 1987; 162: 156-159.

15. Jimi E, Ikebe $T$, Takahashi $N$, Hirta $M$, Suda $T$, Koga, $T$. Interleukin-l $\alpha$ activates an NF- $\kappa$ B-like factor in osteoclast-like cells. J Viol Chem 1996; 271: 4605-4608.

16. Takeshita A, Chen Y, Watanabe A, Kitano S, Hanazawa S. TGF- $\beta$ induces expression of monocyte chemoattractant JE/ Monocyte Chemoattractant Protein 1 via transcriptional factor AP-1 induced by protein kinase in osteoblastic cells. $J$ Immunol 1995; 155: 419-426.

17. Brown LF, Yeo K-T, Berse B et al. Expression of vascular permeability factor (vascular endothelial growth factor) by epidermal keratinocytes during wound healing. J Exp Med 1992; 176: 1375-1379.

18. Nauck M, Karakiulakis G, Perruchoud AP, Papakonstantinou E, Roth M. Corticosteroids inhibit the expression of the vascular endothelial growth factor gene in human vascular smooth muscle cells. Eur J Pharm 1998; 341: 309-315.

19. Matsushita K, Motani R, Sakuta T et al. Lipopolysaccharide enhances the production of vascular endothelial growth factor by human pulp cells in culture. Infect Immun 1999; 67: 1633-1639.

20. Nagashima $M$, Yoshino $S$, Aono $H$, Takai M, Sasano $M$. Inhibitory effects of anti-rheumatic drugs on vascular endothelial growth factor in cultured rheumatoid synovial cells. Clin Exp Immunol 1999; 116: 360-365.

21. Tischer E, Mitchell R, Hartman $\mathrm{T}$ et al. The human gene for vascular endothelial growth factor: multiple protein forms are encoded through alternative exon splicing. J Biol Chem 1991; 266: $11947-11954$ 